\title{
Ponseti Technique is the Best Option for the Treatment of Idiopathic Congenital Club Foot by the Age of Two Years
}

\author{
Md Mostafizur Rahman ${ }^{1 *}$ \\ Shafiqul Islam \\ Abdur Rouf' \\ Md Abdul Momen \\ Md Zahidul Islam \\ Md Abdul Ohab \\ Md Ashfaqur Rahman' \\ Bablu Kumar Shaha ${ }^{2}$
}

'Department of Orthopedics \& Trumatology Rangpur Medical College

Rangpur, Bangladesh.

${ }^{2}$ Department of Pediatric Surgery

Rangpur Medical College

Rangpur, Bangladesh.

\author{
${ }^{*}$ Correspondence to: \\ Dr. Md Mostafizur Rahman \\ Assistant Professor \\ Department of Orthopedics \& Traumatology \\ Rangpur Medical College \\ Rangpur, Bangladesh. \\ Mobile : +8801715010986 \\ E-mail : sujonmostafiz@yahoo.com
}

www.banglajol.info/index.php/CMOSHMCJ

\begin{abstract}
Club foot is the commonest congenital deformity in babies. Around $80 \%$ of the cases occur in developing nations. There are many option for treating club foot, Ponseti technique is one of them. This prospective interventional study was carried out at the Department of Orthopaedic \& Traumatology, Rangpur Medical College Hospital, over period of 3 year from 22/09/2011 to 22/12/2014. One hundrad and Fifty patients of two hundrads and twenty three foots were treated by ponseti technique and followed up for the purpose of this study. Both rigid and non rigid variety of club foot were treated irrespective of sex and side of foot involvement. Pirani scoring system was used to assess the severity of deformity, needs of tenotomy and evaluation of result. All the patients were treated by Ponseti technique, only $83(11.1 \%)$ foot by plaster, $140(88.9 \%)$ foot required tenotomy. There were complication of $29(13 \%)$ foot of 19 patients in the form of plaster sore. All patients were under bracing protocol. In this study it is found that $94.61 \%$ satisfactory result. So Ponseti technique is a safe, effective \& low cost and easily acceptable. So it is the best option for the treatment of idiopathic congenital club foot under the age of two years.
\end{abstract}

Key words : Idopathic congenital club foot; Ponseti technique; Pirani scoring system; Plaster sore.

\section{INTRODUCTION}

Club foot is the commonest congenital deformity in babies. More than 100,000 babies are born worldwide each year with congenital club foot. Around $80 \%$ of the cases occur in developing nations ${ }^{1-3}$. Club foot is a complex deformity in which the foot is completely turned inward at birth. Idiopathic club foot occurs worldwide with an incidence varying from 0.39 to 8 per 1000 live births. It is the seventh amongst common congenital defect and the first for the musculoskeletal system. There are many option for treating club foot, Ponseti technique is one of them ${ }^{3-6}$.

The Ponseti technique involves gentle staged correction of the deformities of club foot. Weekly manipulations are performed and the foot is cast in plaster of paris at the maximum correction at the end of every manipulation. The cast is removed before the next manipulation and the correction is slowly increased. In many cases full correction is aided by percutaneously tenotomy prior to the application of the last cast. Once full correction of the club foot has been achieved, the patient is given a Denis Browne splint to maintain the correction ${ }^{7}$. This must be worn full time for the first three months and thereafter at night up to the age of four years. 


\section{MATERIALS \& METHODS}

The present prospective interventional study was carried out at the Department of Orthopaedic \& Traumatology, Rangpur Medical College Hospital, over period of 2 years from 22/09/2011 to 22/12/2013 to evaluate the result of treatment of idiopathic congenital club foot by Ponseti technique under the age two years. Patients of idiopathic congenital club foot attended at Rangpur Medical College Hospital were the study population. A total of 150 patients of 223 foot (Both rigid and non-rigid variety, unilateral or bilateral) under the age of 2 years irrespective of sex, were included in the study. Patients with other congenital deformity, relapsed club foot, neglected club foot and age above 2 years and drop out cases also were excluded from the study.

\section{RESULTS}

Table 1 : Distribution of patients by sex.

\begin{tabular}{lcr} 
Sex & No of patients & Percent \\
Male & 98 & 64.7 \\
Female & 42 & 34.3 \\
Total & 150 & 100.0 \\
\hline
\end{tabular}

Table 2 : Distribution of the patients by involvement of foot.

\begin{tabular}{lcc} 
Involvement of foot & No. of foot involved & Percent \\
Right & 43 & 28.7 \\
Left & 34 & 16.7 \\
Bilateral & 73 & 50.0 \\
Total & 150 & 100.0 \\
\hline
\end{tabular}

Table 3 : Distribution of type of club foot.

\begin{tabular}{lcc} 
Type of club foot & Frequency & Percent \\
\hline Rigid & 140 & 62.79 \\
Non Rigid & 83 & 37.21 \\
Total & 223 & 100.0
\end{tabular}

Table 4 : Distribution of score before tenotomy.

\begin{tabular}{lrr} 
Final score & No. of foot & Percent \\
0 & 83 & 80 \\
0.5 & 120 & 15.6 \\
1 & 20 & 4.4 \\
Total & 223 & 100.0 \\
\hline
\end{tabular}

Table 5 : Distribution of the foot by tenotomy.

\begin{tabular}{lcc} 
Tenotomy & No of foot & Percent \\
Done & 140 & 88.9 \\
Not done & 83 & 11.1 \\
Total & 223 & 100.0 \\
\hline
\end{tabular}

Table 6 : Distribution of score after tenotomy.

\begin{tabular}{lcc} 
Final score & No. of foot & Percent \\
0 & 128 & 80 \\
0.5 & 10 & 15.6 \\
1 & 02 & 4.4 \\
Total & 140 & 100.0 \\
\hline
\end{tabular}

Table 7 : Distribution of the final score.

\begin{tabular}{lcc} 
Final score & No. of foot & Percent \\
0 & 211 & 80 \\
0.5 & 10 & 15.6 \\
1 & 02 & 4.4 \\
Total & 223 & 100.0 \\
\hline
\end{tabular}

Table 8 : Distribution of the patients by final outcome.

\begin{tabular}{lcr} 
Result & Frequency & Percent \\
Satisfactory & 211 & 94.61 \\
Unsatisfactory & 12 & 5.39 \\
Total & 223 & 100.0 \\
\hline
\end{tabular}

Table 9 : Distribution of the patients by complication.

\begin{tabular}{lcc} 
Result & Frequency & Percent \\
Complication & 29 & 13 \\
No complication & 194 & 87 \\
Total & 223 & 100.0 \\
\hline
\end{tabular}

Among 150 club foot baby of 211 foot had Satisfactory (94.61\%) outcome, 12 (5.39\%) unsatisfactory outcome. In this study it is found that $94.61 \%$ satisfactory result among 223 foot of 150 patients of idiopathic congenital club foot treated by Ponseti technique. It is quite acceptable outcome. 


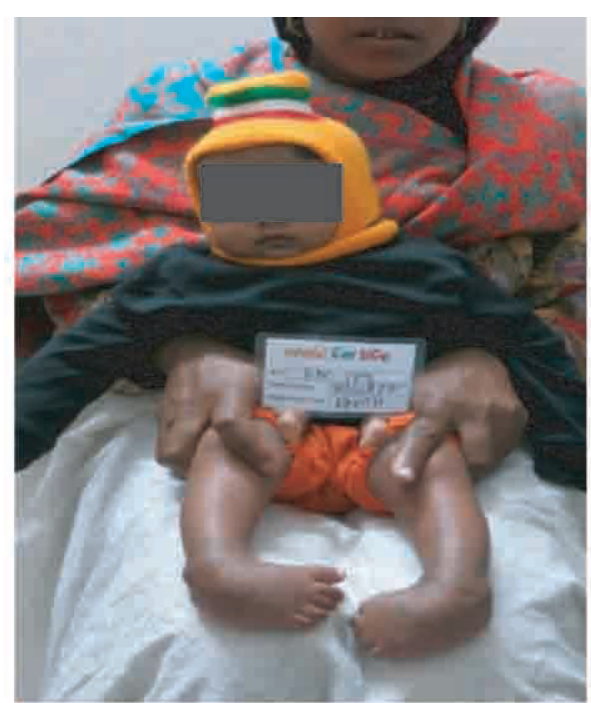

Figure 1 : Photograph of club foot patient.

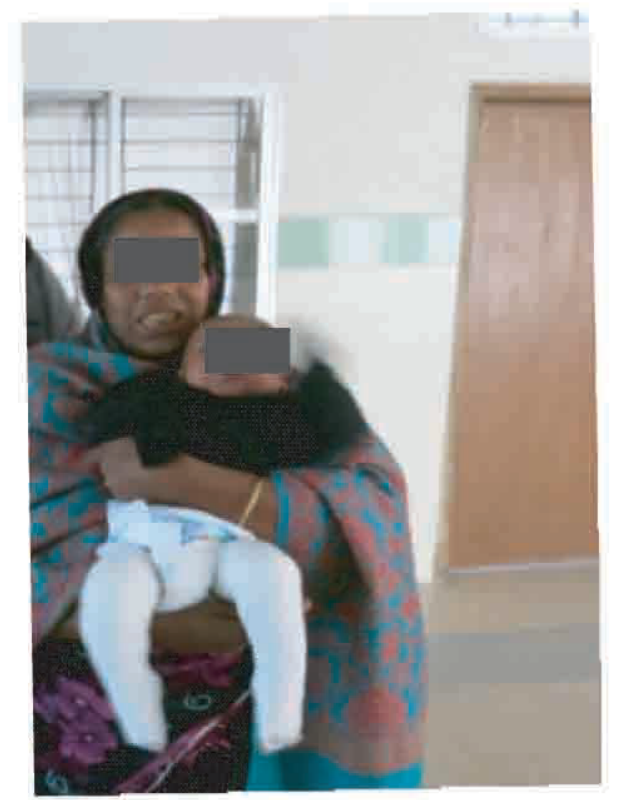

Figure 2 : Club foot corrected by plaster.
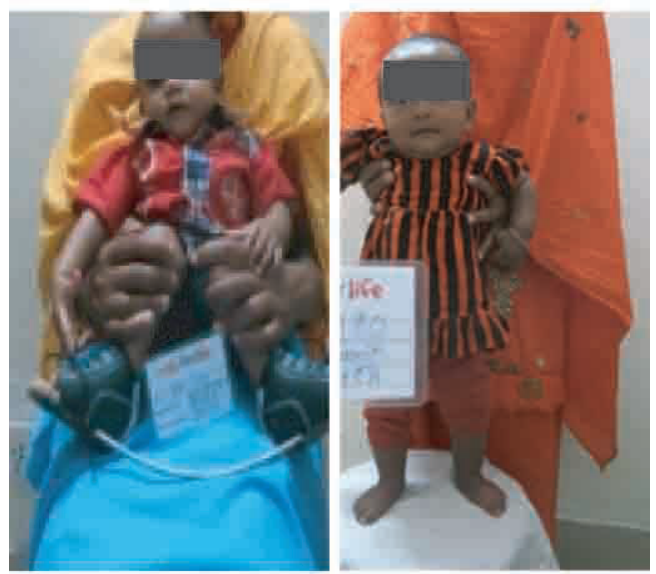

Figure 3 : Bangla Brace, after 3 months.

\section{DISCUSSION}

Club foot is a complex deformity of foot and ankle in which fore foot is adductes, mid foot cavus, hind foot varus and ankle equinus with concomitant soft tissue abnormalities.

It is the seventh amongst common congenital defect and the first for the musculoskeletal system. Idiopathic club foot occurs worldwide with an incidence varying from 0.39 to 8 per 1000 live births ${ }^{4}$.

In this study, within 150 cases, the male patients were more frequent than female patients which are 98(64.7\%) and $42(34.3 \%)$ respectively. Percentage of male patients was higher than female.

In $150 \mathrm{club}$ foot patients, bilateral involvement of foot was observed in $73(50 \%)$ cases. The unilateral right foot involvement is $43(28.70 \%)$ and left foot involvement is $34(16.7 \%)$. Among all deformed foot $160(62.79 \%)$ foot of 102 patients had rigid variety and $83(37.21 \%)$ foot of 48 patients had non-rigid variety. Percentage of rigid was higher than non rigid variety.

In this study out of 223 feet $140(88.9 \%)$ feet of 102 patients was corrected by plaster with tenotomy and 83 (11.1\%) feet of 48 patients by plaster only. Percentage of tenotomy was higher than in comparison to without tenotomy.

In the 223 foot, 194 (87\%) foot of 131 patients had no complication and 29 (13\%) foot of 19 patients had complication (plaster sore).Percentage of no complication was higher than in comparison to with complication.

All the patients under braceing protocol (Bangla Brace) was used. The difficult part of this study was maintenance of bracing protocol. Initial two or three days were the critical period as reported by the parents. After that patients were adjusted with splint.

Out of 223 foot, after correction 211 foot $(80 \%)$ had final Pirani score 0 which is normal, in 10 foot $(15.6 \%)$ final Pirani score was 0.5 which is moderately abnormal, in 2 foot $(4.4 \%)$ final Pirani score was 1 which is severely abnormal. Percentage of final score 0 was higher than in comparison to with final score 0.5 and 1.8 . In this study it is found that $94.61 \%$ satisfactory result among 223 feet of 150 patients of idiopathic congenital club foot treated by Ponseti technique. It is quite acceptable outcome. In this study the average follow up period for these patients were 6 months.

\section{CONCLUSION}

Ponseti technique is the best method for treatment of idiopathic congenital club foot. The difficult part of this technique was maintenance of bracing protocol. Initial two or three days were the critical period as reported by the parents. After that patients were adjusted with splint.

\section{DISCLOSURE}

All the authors declared no competing interest. 


\section{REFERENCES}

1. Ponseti 'Congenital Club foot: Fundamentals of Treatment', Oxford, England: Oxford University Press.1996;4

2. Ponseti TS, Pirani F, Dietz J, Morcuende V, Mosca J, Herzenberg S, et al. 'Club foot: Ponseti Management. In L. Staheli (ed.) GlobalHelp Organisation. 2003.

3. Ponseti I. 'Scientific basis of management of club foot' Global Help.2009;1:4-5.

4. Abdelgawad AA, Lehman WB, van Bosse HJP, Scher DM, Sala DA, 'Treatment of idiopathic club foot using the Ponseti Method: minimum of two year follow-up', Cooper DM, Dietz FR, 1995, 'Treatment of idiopathic club foot. A thirty-year follow-up note', J Bone Joint Surg Am. 2007;77(10):1477-1489.

5. Gupta A, Singh S, Patel P, Patel J, Varshney MK. Evaluation of the utility of the Ponseti method of correction of club foot deformity in a developing nation. Int Orthop. 2008;32 (1):75-79.

6. Dyer PJ, Davis N. 'The role of the Pirani scoring system in the management of club foot by the Ponseti method', J Bone Joint Surg Br 2006;88(8):1082-1084.

7. Hussaina N, Khanb T, Ahmeda A. 'Complete Subcutaneous Tenotomy of Tendo-Achilles in Club foot Patients - A Four Year Follow Up. 2004;2(1):17-19.

8. Pirani S. 1995, 'A method of assessing the virgin club foot', Orlando, FL: Pediatric Orthopaedic Society of North America (POSNA). 